In the surrounding district, where holss are equally numerum, I have never detected the peculiar note.

This power of imitating the songs of birds is well known to bird-fanciers and clealers; hence birds taken from the nest are considered worthless by those who admire the natural song. I myself had a Siskin that sang the goldfinch's song, and a muthatch that I sent to a bird show came back with a wonderful medley of notes, of which he seemed extremely proud, the call-note of the canary and several notes of the blackbird being amongst those I could clearly recognise.

J. YOUNO

Notting Hill

\section{Harrow School Bathing-Place}

WILL you kindly allow me to appeal through your columns for suggestions how to cure a nuisance which we suffer from year after year in our bathing-place here, and for which we have as yet found no remedy?

The water which is pumped into the bath from a considerable depth is beautifully clear at the beginning of the season, but as soon as the weather becomes hot and the rays of the sun attain power, countless filaments, consisting of conferva, \&c., spring up from the brick floor of the bath, and push their way rapidly to the surface, the clepth of the water varying from about four feet to six feet. As the boys plunge from the side into the water and swim about the bath these long wavy stems are shivered into myriads of fragments, which collect on the surface of the water and form there a disagreeable and ugly scum, which detracts not a little from the pleasure of bathing cluring a great part of the summer term. We have taken some pains to discover a remedy for this, whether by chemical or other means, but as yet have been quite un uccessful. The weed reappears in equal extberance year after year and we are helpless. If any of your readers can contribute to the removal of this annual plague, he would confer a treat benefit on the school, and any practical suggestions would be gratefully received either by G. Griffith, Esq., Harrow, or by

Harrow, April 8

\section{London Clay Fossils}

I SHOULD be glad if any of the contributors to NATURE would lindly inform me of any fossiliferous sections of the London clay at present open in the immediate neighbourhood of Lonclon. Many of those named in Whitaker's "Geology of Londor," such as Highgate, Hampstead Heath, \&c, are closed, while others at Lewi:ham, \&c., yield no fossils except a few fragments of wood.

South Kensington Science Schools, April ${ }_{5}$

\section{Meteor}

As the meteor of April 2 was seen at Ashwell, Herts, and with much the same course and splendour as observed at Leicester (but without any accompanying sound), it must have been very much further off than your Leicester correspondent imagines.

So bright a meteor, falling so early in the evening, cannot fail to have been much observed.

Odsey Grange, Royston, Herts

\section{The Nightingale}

IN case you have recaived no earlier communication to a similar effect, you may possibly think it worth while to record that I heard a nightingale twice on the I 4 th instant, in a planta. tion by the side of Hanger Lane, in Ealing. It was but an abortive song, such as the first of the season is very apt to be, as if he were rather shy of the sotund of his own voice. But there was enough of it to leave no possible doubt as to the identity of the performer. I may add that I have in previous years heard him in the same spot two or three days earlier than elsewhere in this neighbourhood.

I heard the wryneck ("cuckoo's mate") also several times on the same day in Gunnersbury and Hanger Lanes, having heard him once the previous afternoon ( $13^{\text {th }}$ ) in Kew Gardens.

Gtmnersbury, April I 6

G, J, Pearse

\section{FLOATING MAGNETS}

FOR one of my little books of the Experimental Science Series I have devised a system of experiments which illustrate the action of atomic forces, and the atomic arrangement in molecules, in so pleasing a manner that I think these experiments should be known to those interested in the study and teaching of physics.

A dozen or more of No. 5 or 6 sewing needles are magnetised with their points of the same polarity, say north. Each needle is run into a small cork, $\frac{1}{4}$ in. long and $\frac{3}{16}$ in. in diameter, which is of such size that it just floats the needle in an upright position. The eye end of the needle just comes through the top of the cork.

Float three of these vertical magnetic needles in a bowl of water, and then slowly bring down over them the $N$. pole of a rather large cylindrical magnet. The mutually repellent needles at once approach each other and finally arrange themselves at the vertices of an equilateral triangle, thus $\therefore$. The needles come nearer together or go further away as the magnet above them approaches them or is removed from them. Vibrations of the magnet up and down cause the needles to vibrate, the triangle formed by them alternately increasing and diminishing in size.

On lifting the magnet vertically to a distance, the needles mutually repel and end by taking up positions at the vertices of a triangle inscribed to the bowl.

Forr floating needles take these two fims;

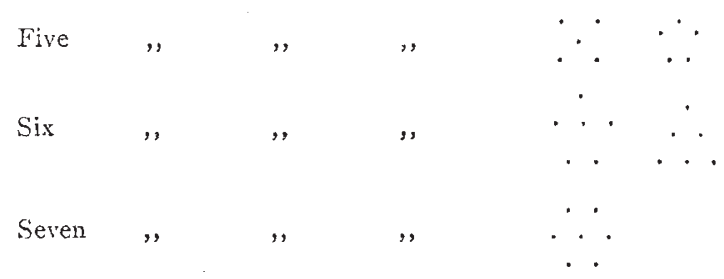

I have obtained the figures up to the combination of twenty floating needles. Some of these forms are stable; others are unstable, and are sent into the stable forms by vibration.

These experiments can be varied without end. It is certainly interesting to see the mutual effect of two or more vibrating systems, each ruled more or less by the motions of its own superposed magnet; to witness the deformations and decompositions of one molecular arrangement by the vibrations of a neighbouring group, to note the changes in form which take place when a larger magnet enters the combination, and to see the deformation of groups produced by the side action of a magnet placed near the bowl.

In the vertical lantern these exhibitions are suggestive of much thought to the student. Of course they are merely suggestions and illustrations of molecular actions and forms, for they exhibit only the results of actions in a plane; so the student should be careful how he draws conclusions from them as to the grouping and mutual actions of molecules in space.

I will here add that I use needles floating vertically and horizontally in water as delicate and mobile indicators of magnetic actions, such as the determination of the position of the poles in magnets, and the displacement of the lines of magnetic force during inductive action on plates of metal, at rest and in motion.

The vibratory motions in the lines of force in the Bell telephone have been studied from the motions of a needle (floating vertically under the pole of the magnet), caused by moving to and fro through determined distances, the

I A note on Fxperiments with Floating Magnets, by Alfred M. Mayer. Reprinted from the America: Fournal of Science. 
thin iron plate in front of this magnet. These experiments are worth repeating by those who desire clearer conceptions of the manner of action of that remarkable instrument.

\section{SUN-SPOTS AND TERRESTRIAL MAGNETISH}

I $\mathrm{N}$ a remarkable article on "La Météorologie Cosmique," which has appeared in the Annuairc of the Bureau des Longitudes, for $1878, M$. Faye says with reference to the influence of sunspots on the earth's magnetism, that the observations of Cassini "give $17 \delta 7$ " 25 for the date of the maximum observed then at Paris, whilst the latest observations--those of $\mathrm{Mr}$. Broun, himself at Trevandium-assign $3 \delta 70.85$ for the epoch of the last maximum. The interval is 83.60 years. On dividing this by $\delta$, the number of periods in this interval, 10.45 years, are found for the duration of the period. That is to say, almost exactly the value already found by I,amont by means of his own observations at Munich. The period of the spots deduced by M. Wolf, II'I years, not being equal to that for the magnetic variations, these two phenomena have no relation to each other."

I desire to offer a remark on this conclusion, which seems to me too hasty. On examining the two periodic series, that for the diurnal variation of declination and that for the frequency of the solar spots, we sec that there is a perfect coincidence in their phases though the length of successive periods is not constant. We may find a mean length of ten, elesen, or more years, according to the epoch from which the calculation is begun, but we shall always find the same length from both scries if we commence at the same date.

It seems to me then that the true way to determine wheth:r there is an intimate connection between the two Whenomena is to compale their phases, and sce whether the maxima and minima of the one coincide with those of the other. If there is identity in these respects, we must without doubt find the same mean values for the periods.

M. Faye accepts the date $I 787^{\circ 25}$ as that of a maximum for the oscillations of the declination. If we look then at the curve, Fir. 2, given by him in the article in question, we see that this corresponds exactly with a maxirnum of sun-spot frequency. In like manner similar coincidences are seen in the epochs deduced from the obeervations of Arago and others up to the present time when comparcd one by one with the sun-spot observations of Schwabe, Carrington, Secchi, as well as of those mide at Kew. The conclusion seems to me very different from that of M. Faye. We are entitled to apply the rule he bas given (p. 634): "If two series of phenomena, however different they may appear at first, follow exactly the same period, they ought to be referred to the same cause."

There is another passage upon which I desire to offer a remark: "Two kinds of meteors exercise a considerable influence on the direction of the magnetic needle, these are the aurorx boreales and the cyclones."

For the first there is a general agreement, but for the cyclones what observations have we which prove any such influence? If cyclones exercise a considerable influence on the direction of the needle, in what phase of the phenomenon does this occur? Is it on their formation, on their passage over some particular meridian, or when their centre is over a place? In the last case each cyclone will be a source of disturbance, which will be manifested as it progresses, and not simultaneously at all places, which, however, is what really occurs in the case of magnetic disturbances. Electricity is, without doubt, a cause, but only in the case of such considerable discharges as the aurora polaris; but not the local electricity which may accompany cyclones. When there is a storm, and the thunder rolls, and the electrometer shows enormous variations of atmospheric clectricity, changing sign continually, the magnetic needle continues its usual and regular progress. Of this we can offer hundreds of examples.

\section{Lisbon, February 22}

P.S. - The mean movements of the magnetic needle in the Lisbon Observatory, from eight A.M. to two P.M. are given in NATURE, vol. xiii. p. 448 , for the years 1858 to I 875 ; the following are the corresponding mean ranges for the next two years :-
1876
$5.81^{\prime}$
I 877
$54^{\prime}$

So that the mean movement was less in 1877 than in I 876 .

\section{OUR ASTRONOMICAL COLUMN}

New COMPANION TO AldmBaran.-Mr. S. W. Burnham notifies his discovery with the $\mathrm{S} \delta \frac{1}{2}$-inch Alvan Clark refractor of the Dearborn Observatory, of a minute star much nearer to Aldebaran than that which makes the double star H. VI. 66; be compares it with the ruddy bright star, as resembling, in difficulty and appearance, Mars and his outer satellite. The mean of three days' observations gives the angle $109^{\circ} \circ$, and the distance $30^{\prime \prime} \cdot 35$ for $1877^{\circ} 90$, or if the second result which, as printed, differs nearly ten degrees from the other two, the angle will be II I $^{\circ} 9$. The secular proper motion of Aldebaran, according to Mädler, is $19^{\prime \prime} \mathrm{I}$ in the direction $157^{\circ}$; some years must elapse before the question of physical or optical duplicity can be decicled. Eight days' measures of the close companion of Sirius, by Mr. Iurnham, with the same instrument, assign for the angle of position $52^{\circ} \cdot 4$, distance $10^{\prime \prime} \cdot \delta_{j}$ at the epoch 1877.97.

THE STAR LALANDE 378J3.-Mr. J. E. Gore writes from Ballisodare, Co. Sligo, with reference to this star, which appears in the reduced catalogue as a sccond magnitude, and which, observing in the I'unjab in August, I 877 , he had found a little less than Lacaille 8308 or $7 \mathrm{~m}$. This is one of the errors in the catalogue which, as in a case recently noticed in this column, can only be cleared up by referring to the Histoirc Céleste. The observation was made on August 20, 5795 , and the star No. 378r 3 was really estimated $7.8 \mathrm{~m}$. " $\Lambda$ quilæ was observed immediately before it, and entered $2 \mathrm{~m}$.; it is this erroneous magnitude for the bright star of Aquila that has become attached to the star of which Mr. Gore writes. There is a very noticeable proper motion in N.P.D., apparently about $+0^{\prime \prime} 48$ annually, as shown by comparison of the observations of Lacaille, Lalande, Jacob, and Argelander, with the position in the Washington Catalogue for I 860.

The Minor Planets.-Discoveries in this group still progress. No. I 86 was detected by M. Prosper Henry at Paris, on April 6, shining as a star of $11.5 \mathrm{~m}$., and No. I 87 by M. Coggia at Marseilles, on April ro; it was estimated 10 m. No. I78 (Palisa, 1877, November 6) has been named Belisana, and No. I84 (Palisa, I878, February 28) it is proposed to call Deiopeic. With already seven additions to the list, it would not appear that I878 is likely to fall short of the most prolific of preceding years in these discoveries.

The Transit of MERCURy on MAy 6.-If we calculate strictly from Le Verrier's tables of sun and planet, using therefore the value of the sun's diameter which he deduced from the transits of Mercury in his memoir, printed as an addition to the Connaissance des Temps for i 848 , we shall have the following formula for determining the time of the first exterual contact of limbs in the approaching transit:-

$t={ }_{3}$ h. 13 m. Is. $-\left[r^{\circ} 8723\right] r \sin l-\left[I^{\circ} 9079\right] r \cos l, \cos \left(L_{-}^{\circ}-5^{\circ} 49^{\prime} 3\right)$ in which $t$ is the Greenwich mean time of contact, $r$ the 